\title{
Social uncertainties related to stable iodine intake in a nuclear emergency
}

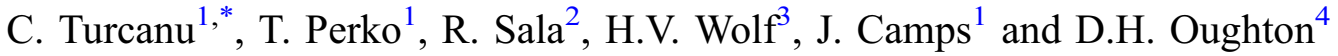 \\ ${ }^{1}$ SCK-CEN-Belgian Nuclear Research Centre, Mol, Belgium. \\ 2 CIEMAT-CISOT - Sociotechnical Research Centre, Barcelona, Spain. \\ ${ }^{3}$ UA-University of Antwerp, Antwerpen, Belgium. \\ ${ }^{4}$ NMBU/CERAD - Norwegian University of Life Sciences, Centre for Environmental Radioactivity, Ås, Norway.
}

\begin{abstract}
Intake of stable iodine intake is considered as an effective countermeasure for reducing the risk of thyroid cancer in an eventual release of radioactive iodine following nuclear accident. However, there are a number of value and social uncertainties that are likely to impact on accident management. These include differences in public response as well as decisions made by emergency management actors during an actual incident. In order to explore these sources of uncertainty, this paper explored social uncertainties related to the potential administration of stable iodine. First, public understanding and compliance with the advice of authorities was studied by surveys, showing that less than half of the public knew when iodine tablets should be taken, or understood their protective role. There were also country specific differences in the level of expected compliance with authorities' advice. Second, social uncertainties were identified through observations of emergency exercises; these were revealed to be mainly related to timing, public response, communication, effectiveness, cross-border issues and first responders. Third, studies on factors influencing communication about stable iodine were carried out and showed that public understanding and compliance with advice could be improved by communicating numerical and narrative information. Overall, the results indicate that enhanced focus on social uncertainties during the preparedness phase may improve the effectiveness of stable iodine administration in case of an emergency.
\end{abstract}

Keywords: social uncertainties / stable iodine / nuclear emergency / CONFIDENCE

\section{Introduction}

The administration of stable iodine, usually in the form of potassium iodide (KI) pills, is considered an efficient countermeasure in case of an accidental release of radioactive iodine, specifically to reduce the risk of thyroid cancer (Jourdain et al., 2010; Dreger et al., 2015; WHO, 2017). When radioactive iodine from an accidental release is inhaled during cloud passage or ingested after food has been contaminated by deposition or irrigation with contaminated water it will concentrate in the thyroid gland. By the administration of KI, ranging typically from $16 \mathrm{mg}$ for neonates to $130 \mathrm{mg}$ for adults (WHO, 2017), an abundant amount of stable iodine will be available for uptake by the thyroid gland, saturating it with stable iodine and avoiding largely the uptake of radioactive iodine. The effectiveness of stable iodine administration in terms of the protective effect for uptake of radioactive iodine by the thyroid gland has been studied extensively (Broggio et al., 2019). The correct time of intake of stable

\footnotetext{
*Corresponding author: catrinel.turcanu@sckcen.be
}

iodine relative to the intake of radioactive iodine is very important for the protective effect. When stable iodine is taken 36 hours or less before the intake of radioactive iodine the protective effect can be $80 \%$ or more with little age dependence. If $\mathrm{KI}$ pills are taken after the intake of radioactive iodine the protective effect decreases rapidly with the time delay. KI administration 6 hours after radioactive iodine intake results in a protective effect of less than $50 \%$ and is very similar for all age categories (Broggio et al., 2019).

The increase in thyroid cancer after the exposure of the thyroid gland and the protective effect of stable iodine administration on radioactive uptake by the thyroid gland is well known. However, a systematic scientific review of the effects of KI administration on reduction of thyroid cancer after accidental releases, especially in children, has only recently been demonstrated by the WHO (Dreger et al., 2015). Since Chernobyl data are the most comprehensive and reliable data available describing the relation between thyroid radiation and dose and risk for thyroid cancer (Jourdain et al., 2010), the studies in the WHO review all relate to the Chernobyl accident. Thyroid exposures in Fukushima residents are much lower than those from the Chernobyl accident, and no strong 


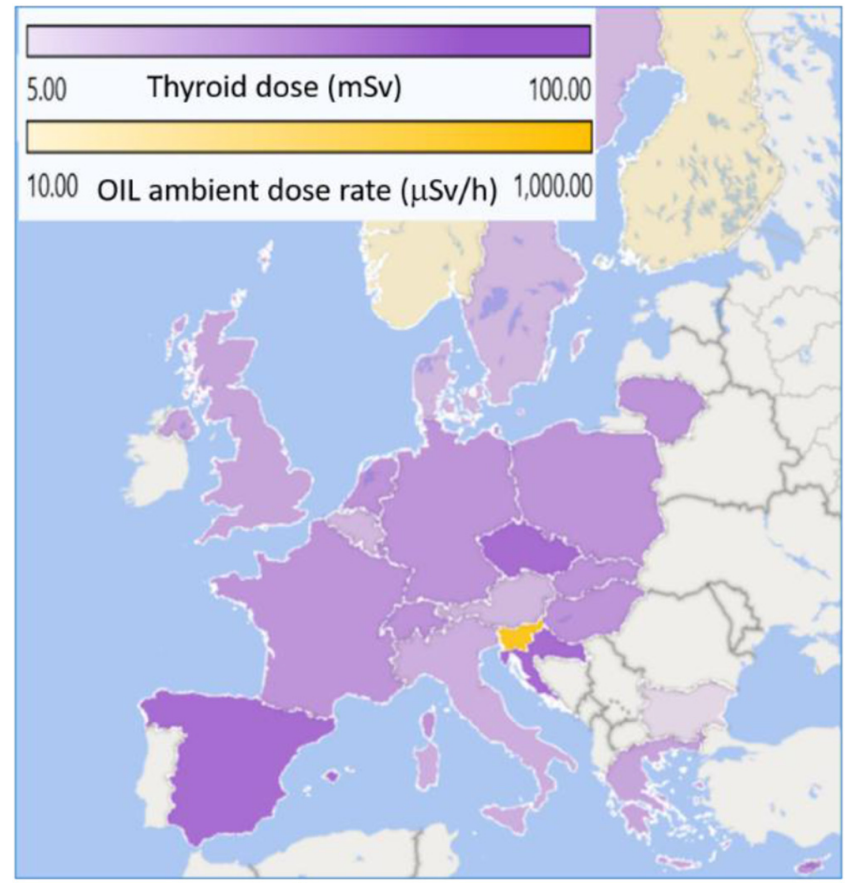

Fig. 1. Reference levels for the administration of stable iodine for children $(<18 \mathrm{y})$ in different European countries (HERCA, 2019). Some countries have specified reference levels in terms of thyroid dose, others in terms of operational intervention levels (OIL) on ambient gamma dose rate.

evidence in support of a causal relation of thyroid cancer with radiation exposure in Fukushima is available so far (Yamashita et al., 2018).

Because of the strong evidence in the effect of KI administration on radioactive iodine uptake, iodine prophylaxes with the purpose to limit the uptake of radioactive iodine are widely recommended by international organizations (ICRP, IAEA, WHO) and implemented in many national nuclear emergency plans (Yamashita et al., 2018). However, the way of implementation varies between different countries, largely due to differences in expert opinion (Dreger et al., 2015). National implementation includes decisions on the (area of) pre-distribution, reference dose levels, time of intake, or combination with other countermeasures, among others. Figure 1 shows reference levels for stable iodine prophylaxis for children $(<18 \mathrm{y})$ in different European countries, based on the country fact sheets collected by HERCA (2019). Most countries use the thyroid organ dose as reference criteria; however some have also implemented operational intervention levels based on an ambient dose rate criteria. Although it is impossible to map all details specific to different countries (some countries use ranges or different dose criteria, e.g. integrated over a different time period), Figure 1 shows clearly the large differences in the preparedness for stable iodine administration. In events with cross border consequences, these differences could be an important source of uncertainty and HERCA (2019) has taken the initiative to coordinate harmonization in case of an accident with cross border consequences. Apart from reference levels and associated regions of administration, also the timing of administration, single or repeated administration could be a source of uncertainty in the management of a nuclear emergency in which radioactive iodine is either actually or potentially released to the environment.

Such differences in opinions about iodine administration, even within the preparedness phase, are examples of value uncertainties that can impact on accident management (French et al., 2020). In the event of a nuclear accident, the use of iodine tablets is likely to be impacted by other social and ethical uncertainties linked to public response, as well as decisions made by emergency management actors during the actual incident. In order to explore these sources of uncertainty, this paper addresses three areas of social uncertainty related to the potential administration of stable iodine as a countermeasure. Firstly, public understanding and compliance with the advice of authorities, as studied by surveys; secondly the implementation of this countermeasure by emergency preparedness actors as investigated by observations of emergency exercises, and finally the communication about iodine tablets' administration.

\section{Social uncertainties related to stable iodine intake among potentially affected publics}

Surveys were carried out in Belgium and Spain to investigate public's knowledge about protective iodine tablets and the self-reported likelihood of compliance with official advice for iodine tablet intake. In Belgium, data were collected using Computer Assisted Personal Interviews (personal interviews at the home of the respondents, with answers directly coded on a portable laptop or tablet), from November 2017 to February 2018 (national sample), and September 2017 to January 2018 (local population sample). The national sample $(N=1085)$ is representative for Belgian $18+$ adults with respect to gender, age, education, level of urbanisation of the living habitat and province. Among local residents, respondents were adults aged 18 years and older, living within $20 \mathrm{~km}$ around the nuclear installations of Tihange (156 respondents) and Doel (159 respondents). This radius corresponds to the area of preventive distribution of iodine tablets at the time of the survey. In Spain, respondents older than 18 years were recruited from online panels. Data were collected in November 2017 and January 2018. A sample of 302 participants was selected from residents living closer than $30 \mathrm{~km}$ from one of five Spanish nuclear power plants (Vandellós, Ascó, Cofrentes, Trillo and Almaraz). This area corresponds to protective measures in case of an accident (urgent measures $0-10 \mathrm{~km}$, long-term measures $10-30 \mathrm{~km}$ ). A second sample of 506 participants was recruited from people living between $31 \mathrm{~km}$ and $100 \mathrm{~km}$ from at least one of these power plants. This allowed comparison with Belgium, where almost each municipality is located within $100 \mathrm{~km}$ from a nuclear power plant. Soft-quotas were introduced for gender, age and education. Finally, a few questions linked to the public's trust in and compliance with authorities' advice following a nuclear accident were included in the national barometer survey on radiation protection carried out by the Norwegian Radiation Protection Authority every three to four years. However, in Norway only respondents younger than $40 \mathrm{y}$ old were asked whether they would take an iodine tablet 


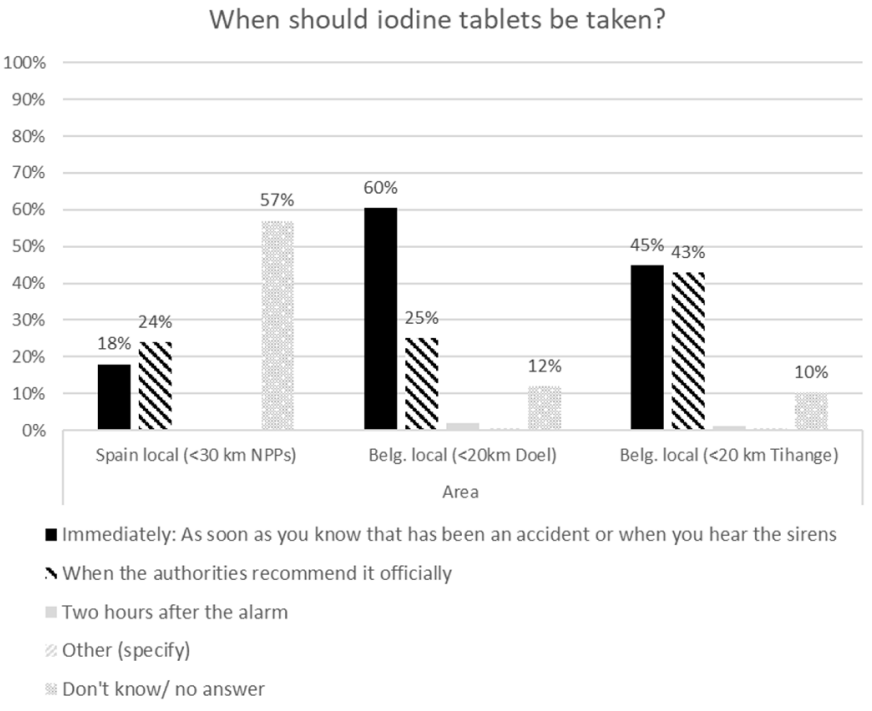

Fig. 2. Knowledge about the intake time of stable iodine tablets.

themselves. This was conducted by telephone interview on 1000 persons in September 2017 (Turcanu et al., 2018).

The results show that among the local residents in Belgium, one in three respondents had iodine tablets at home. However, $80 \%$ respondents or more among the local residents in Belgium knew that these tablets can be obtained from the local pharmacy and about $70 \%$ knew that they can be obtained for free. In Spain, only 27\% among respondents living closer than $30 \mathrm{~km}$ from a nuclear power plant knew that the tablets can be obtained from the pharmacy, while $61 \%$ did not know where to obtain the tablets.

Many respondents in both of the target populations in Spain and Belgium did not know when iodine tablets should be taken (see Fig. 2 for results in the local populations). Only between $24 \%$ and $43 \%$ answered that tablets should be taken after recommendations from authorities, and $57 \%$ of the Spanish population recognised that they did not know when to take the tablets.

Furthermore, when asked about the protective role of iodine tablets, at least half of the respondents among local residents or the general public in Belgium knew these can protect against thyroid cancer, while in Spain less than $20 \%$ gave this response. Instead, half of the respondents in both Spanish samples said they didn't know what the protective role was of iodine tablets. In both Belgium and Spain, large fractions in both local populations and those living farther away thought that iodine tablets can protect against any health effect from ionising radiation (see Tab. 1).

Overall, compliance with taking stable iodine tablets was higher in Belgium than Spain: $84 \%$ of the local residents in Belgium (also $84 \%$ among $40 \mathrm{y}$ old or younger) said they would definitely or probably take an iodine tablet when advised to do so compared to $52 \%$ of Spanish residents living closer than $30 \mathrm{~km}$ from a nuclear power plant (49\% among $40 \mathrm{y}$ old or younger). For the general public, $77 \%$ would follow advice in Belgium ( $70 \%$ among 40 y old or younger), compared to only $28 \%$ of the Spanish respondents living further away ( $29 \%$ among 40 y old or younger). Similar responses were obtained in Belgium with respect to self-reported compliance with the advice to give iodine tablets to children (the question was not asked in Spain). Moreover, in Belgium, $37 \%$ in the Tihange area and $43 \%$ in the area of Doel say they would probably or definitely take the iodine tablets in case of an emergency, even if the authorities say it is not necessary. This may lead to unnecessary intake of tablets. Following a study in France in the aftermath of the Fukushima accident, Crépey et al. (2013) suggest that pharmacies could help identify such an issue and advice about the proper use of tablets.

Surveys carried out in Norway also showed a high level of compliance with authorities' advice, where between 79 and $81 \%$ of those younger than 40 years old answered that they would follow the advice of authorities regarding iodine tablets (Turcanu et al., 2018).

\section{Potential uncertainties recognized during emergency exercises}

Research conducted in CONFIDENCE through observation of exercises provided insights into the uncertainties that may appear during a real nuclear emergency management (Perko et al., 2019). The methodological approach relied on non-participant observation as a technique for the systematic study of human behaviour. It focused on the information flow and communication between actors, as well as the assumptions and decisions made under emergency exercise conditions. Eleven national exercises were observed in six countries, as well as one international exercise, with a total of 29 observation points.

A first observation concerning stable iodine was that in some exercises decision-makers were uncertain about the timing for advising stable iodine intake, specifically when should this measure be implemented, what is the optimal time for administration, and is there enough time for implementation. The following quotes noted during the observation reflect this uncertainty: "We should instruct people to take the pills now, it is established in the emergency plan. - Other says: No, we do not have time for this! We will distribute iodine tablets in the gathering points/areas hosting people". Concerns about sensitive and specific population groups caused additional uncertainties: "They do not know what to propose for pregnant women and children."

Uncertainties related to public response were also noticed, for instance whether iodine tablets distribution will generate queues, or whether potential chaos is to be expected. The exercises also revealed uncertainties due to communication ("Person X has no information about preparation of iodine prophylaxis: 'Was the instruction sent? This information is not provided."').

Additional uncertainties concerned the effective distribution of stable iodine pills: What is the best way to organize the distribution of iodine tablets, do people have access to these tablets, do they know where to find them, what would happen in summer if there were tourists in the area? For instance: "They realized that iodine have not been distributed. Should we bring iodine tablets in the school buses?"; "They do not know if iodine tablets have to be distributed before evacuation or not"; "Iodine tablets have been delivered on $81 \%$ - more than 47500 citizens did not take over the KI pills within the new campaign."

Cross-border issues also caused uncertainties. In some countries, people have iodine tablets at home, while other 
Table 1. Knowledge about the protective role of stable iodine tablets ( $\%$ of respondents selecting different response categories to the question "In your opinion, stable iodine tablets would protect against...”).

\begin{tabular}{|c|c|c|c|c|c|}
\hline In your opinion, stable iodine tablets would protect against $\mathrm{a}^{\mathrm{a}}$.... & $\begin{array}{c}\mathrm{BE} \\
\text { national }(\%)\end{array}$ & $<20$ km Doel (\%) & $\begin{array}{c}<20 \mathrm{~km} \\
\text { Tihange }(\%)\end{array}$ & $\begin{array}{c}\mathrm{ES} \\
<30 \mathrm{~km}(\%)\end{array}$ & $\begin{array}{c}\mathrm{ES},> \\
30 \mathrm{~km}(\%)\end{array}$ \\
\hline Lung cancer & 8 & 5 & 3 & 5 & 6 \\
\hline Thyroid cancer & 50 & 60 & 52 & 17 & 18 \\
\hline Any health effect from ionising radiation & 40 & 34 & 39 & 38 & 35 \\
\hline Other & 3 & 4 & 1 & 6 & 5 \\
\hline
\end{tabular}

a Multiple choice, including “don't know/no answer".

countries foresee open distribution centres. The differences in intervention levels between countries mentioned above were also noted, as were the different limitations for different population groups (e.g. children). For instance, in one country they may distribute iodine to children only, while in a neighbouring country they apply the action to the whole population. The following quotes reflect these uncertainties: "You are not able to provide iodine tablets to your neighbours. You would give tablets to your children, but what about our children. Where would you provide tablets?-At your embassy?"; "We would not wait for a heavy accident. In our country, we don't have iodine pre-distributed to houses. We would immediately start preparing."; "If you consider giving stable iodine you would shelter up to $30-35 \mathrm{~km}$. As a neighbouring country we would give iodine to more than $120 \mathrm{~km}$."

Uncertainties were noticed also in relation to availability of iodine pills for first responders and their awareness about these pills. For instance, do the police have iodine pills and would measurement teams know when to take them: "In fact the information about the discharge is something the measurement teams should get, then they would know e.g. whether or not to take iodine tablets." "Policeman: Where are the iodine pills? Does police has iodine pills?"

\section{Communicating stable iodine intake: Does the message matter?}

As detailed in previous sections, it is crucial that the public is aware of the correct timing of an eventual iodine uptake in case of a radiological emergency. Effective preparatory communication is pertinent to ensure that the population is able to recall the information correctly when needed and that it is willing to follow the advice even in the case of an emergency in order to prevent, or alleviate, potential health risks as pointed out also by Janssens (2013) in relation to the communication in case of the Fukushima accident. While combining several communication channels may be fruitful in reaching the widest audience possible, the news media continue to play a key role in informing the public, "particularly in those areas in which audiences do not possess direct knowledge or experience" (Happer and Philo, 2013, p.321). However, not all news messages are created equal: scholars in the domain of persuasive communication, and health risk communication in particular, have found that messages containing numerical and messages containing narrative evidence differ considerably in their effect on the public and in eliciting the desired responses (e.g., Zebregs et al., 2015), for instance with regards to perceived message credibility and acceptance. In addition, messages combining both numerical and narrative elements may prove to be even more effective (Tomkiv et al., 2016).

In order to study what type of pre-emergency communication is most effective within the realm of news messages, we investigated whether news articles containing numerical messages (e.g. "20 to 40 percent less protection if iodine pills taken too early"), narrative messages (e.g. "Reduced protection if iodine pills taken too early") or messages combining numerical and narrative messages were most effective in eliciting the desired responses. Data were collected through a representative face-to-face survey of the Belgian population $(N=1085)$, conducted over a 3-month-period from December 2017 to February 2018. A between-subjects, posttest-only experiment related to the communication of a stable iodine intake was used to study which messages lead to better responses by the population with regards to their intended behaviour in a radiological emergency, e.g. waiting with the iodine pill intake until advised to do so by authorities.

The experiment consisted of 3 experimental conditions (numerical message $[N=151]$, narrative message $[N=157]$, combined message $[N=159]$ ) and one control group (no message $[N=618])$. The French-speaking language group was randomly divided into the three experimental conditions and each respondent in one of these groups was exposed to a mock news article, which contained one of the three different messages on the importance of waiting for official instructions before the intake of iodine pills. The Dutchspeaking part of the sample formed the control group. They were exposed to a similar parallel experiment, but in their case the news article was related to consumption of food from Fukushima. The control group thus did not receive information about iodine pill intake, but was asked to answer several control questions regarding, for instance, their intended behaviour with respect to waiting with the intake of iodine pills, in order to compare for differences between the responses by experimental and control groups. The experiment tested participants' recall and evaluations of the message, as well as their behavioural intentions regarding the correct intake of iodine pills. In addition, the authors tested whether the effectiveness of different messages 
differed depending on people's predispositions (e.g. sociodemographics, preference for numbers, empathic score, trust in authorities).

Results show that all three message types led to very high correct message recall ${ }^{1}$ (mean: $90.4 \%$ ), with the combined message scoring the highest rate of correct recall (93.1\%). Furthermore, the different types of messages -(numerical, narrative, combined) - were equally effective in communicating about the correct intake of iodine pills: each condition resulted in statistically significantly higher rates $(p=0.01)$ of desired intended behaviour (mean score: 4.09) when compared to the control group (mean score: 3.11$)^{2}$, with the combined stimulus reaching the highest level of agreement (mean score: 4.15). This pattern is reflected in the reduced discomfort respondents in the experimental conditions report regarding an eventual waiting time before the intake of iodine pills when compared to the control group (mean experimental groups: 3.15; control group mean: $3.41 ; p=0.05)^{3}$. After having read the combined message, respondents felt most at ease with waiting for official instructions (mean score: 2.99). With regards to message evaluations, no significant differences in the effects between the specific message types could be established. Levels were stable across the three groups and overall positive: message credibility ${ }^{4}$ received a mean score of 3.1 and message informativeness a mean score of 2.9. With regard to our control variables, it becomes apparent that trust in authorities as well as predispositions towards the issue of nuclear energy are key determining variables. Those respondents with less trust in authorities and more negative attitudes towards nuclear energy were less inclined to rate the article positively and to indicate they would follow the advice.

Communication about the effectiveness of iodine pills when taken correctly invariably had a positive effect on preparing people for a nuclear emergency. People who read the mock news article knew better when to take the iodine tablets and felt more at ease with waiting for official instructions than the control group.

The following guidelines related to the correct intake of iodine tablets are formulated:

- when recommending the intake of iodine pills, communicate clearly that taking stable iodine is important for protection of the thyroid and that, in case of an emergency, people should immediately look for iodine pills and keep them close by. In addition to these core messages, it is

\footnotetext{
${ }^{1}$ Measurement Message Recall: "According to the article, when should you take iodine tablets in case of a nuclear emergency?". Answer options: a) immediately: as soon as you hear about an accident, or if you hear sirens; b) when authorities officially recommend it; c) two hours after alarm; d) other; e) don't know/no answer.

${ }^{2}$ Measurement Intended Behaviour: "In case of a nuclear emergency, I will wait for official instructions before taking iodine tablets". Answer scale: $1=$ strongly disagree, $5=$ strongly agree.

${ }^{3}$ Measurement Reported Discomfort: "I would feel uncomfortable if I needed to wait for official orders before taking iodine tablets". Answer scale: $1=$ very little, $5=$ very much.

${ }^{4}$ Message evaluations were measured by means of 7-point semantic differential adjective scales ranging from $1=$ credible (informative), to $7=$ not credible (not informative).
}

important to also communicate to wait for official instructions before taking the pill. This should be complemented by an explanation as to why one needs to wait with the intake, in order to increase confidence in the communication;

- the issue of why to wait with intake can be communicated in a numerical, a narrative or a combined way. For instance: "Iodine pills protect far less if taken too early, xy (name and expertise of a trusted source e.g. family doctor)" or "The impact of iodine pills is reduced by more than 40 percent if taken too early". Whenever space allows, it is advisable to use both numerical and narrative elements in the message to increase its effectiveness;

- ensure that the public is frequently exposed to your message. This includes repeating messages on different communication channels (newspapers, TV, social media) - the "one message, many voices"-rule - to be able to reach a broad public that includes those difficult to reach via the internet or apps;

- long-term efforts to increase the overall trust in authorities, such as politicians, journalists, scientists and the administration could benefit a widespread positive reception of your message by the public.

\section{Conclusions}

Research carried out in CONFIDENCE shows that general knowledge about iodine tablets is low, both regarding the best time to take these tablets, as well as their protective role. Communication about iodine tablets should include both the best time of intake, as well as an explanation of why it is important to follow this advice. In a real event, the message should be repeated many times using different communication channels, while in the preparedness phase communication should be repeated regularly and its effectiveness evaluated, specifically in connection with iodine distribution campaigns.

While compliance with taking an iodine tablet, either oneself or giving to children, was relatively high in both Belgium and Norway, this was much lower in Spain, showing that in-depth research is needed to clarify this aspect. Noncompliance included both not taking tablets when advised, as well as taking tablets when not recommended.

Uncertainties about the timing of iodine tablets' administration were also seen in emergency actors, where observations of emergency exercises highlighted additional uncertainties related to cross-border differences, communication of advice to both citizens and first responders, and effective organisation of distribution of iodine tablets. Uncovering these uncertainties in the preparedness phase should stimulate reflection on ways to improve emergency planning and can be an incentive for engagement of local communities.

Acknowledgement. The work described in this paper was conducted within the CONFIDENCE project which was part of the CONCERT project. This project has received funding from the Euratom research and training programme 2014 2018 under grant agreement No. 662287. Research reported in this paper was also supported by the Norwegian Research Council, project 263856. The experiment section forms part of 
a $\mathrm{PhD}$ project funded by Flemish Research Foundation, Belgium.

Disclaimer (Art. 29.5 GA). This publication reflects only the author's view. Responsibility for the information and views expressed therein lies entirely with the authors. The European Commission is not responsible for any use that may be made of the information it contains.

\section{References}

Broggio D, Teles P, Vrba T, Berkovskyy V. 2019. Assessment from in vivo measurements of thyroid dose due to iodine-131 inhalation when stable iodine has been administered. Radiat. Meas. 127 (2019): 106144.

Crépey P, Pivette M, Bar-Hen A. 2013. Quantitative assessment of preventive behaviors in France during the Fukushima nuclear crisis. PLoS ONE 8(3): e58385.

Dreger S, Pfinder M, Christianson L, Lhachimi SK, Zeeb H. 2015. The effects of iodine blocking following nuclear accidents on thyroid cancer, hypothyroidism, and benign thyroid nodules: Design of a systematic review. Syst. Rev. 4(1): 126.

French S, Haywood S, Oughton DH, Turcanu C. 2020. Different types of uncertainty. Radioprotection 55(HS1). https://doi.org/10.1051/ radiopro/2020029.

Happer C, Philo G. 2013. The role of the media in the construction of public belief and social change. J. Soc. Polit. Psychol. 1(1): 321-336.

HERCA. 2019. Emergency preparedness and response and EP\&R country fact sheets. France: HERCA-Heads of the European Radiological protection Competent Authorities. Available from https://www.herca.org/index.asp (consulted December 2019).
Janssens A. 2013. EU Basic Safety Standards and European response to the Fukushima accident. Radioprotection 48(5): S19-S26.

Jourdain JR, Herviou K, Bertrand R, Clemente M, Petry A. 2010. Medical effectiveness of iodine prophylaxis in a nuclear reactor emergency situation and overview of European practices. RISKAUDIT Report No. 1337, report to the EC DG Transport and Energy under contract No. TREN/08/NUCL/ SI2.520028.

Perko T, Tafili V, Sala R, Duranova T, Zeleznik N, Tomkiv Y, Hoti F, Turcanu C. 2019. Report on observational study of emergency exercises: List of uncertainties. CONCERT Deliverable D9.28. Available from https://www.concert-h2020.eu/en/Publications.

Tomkiv Y, Perko T, Oughton DH, Prezelj I, Cantone MC, Gallego E. 2016. How did media present the radiation risks after the Fukushima accident: A content analysis of newspapers in Europe. J. Radiol. Prot. 36(2): S64.

Turcanu C, Perko T, Abelshausen B, Sala R, Oltra C, Tomkiv Y, Oughton DH, Liland A, Zeleznik N. 2018. Planned behaviour in nuclear emergency situations. CONCERT Deliverable D9.26. Available from https://www.concert-h2020.eu/en/Publications.

World Health Organization. 2017. Iodine thyroid blocking-Guidelines for use in planning and responding to radiological and nuclear emergencies. ISBN: 9789241550185. Available from https://www.who.int/ionizing_radiation/pub_meet/iodine-thy roid-blocking/en/.

Yamashita S, Suzuki S, Suzuki S, Shimura H, Saenko V. 2018. Lessons from Fukushima: Latest findings of thyroid cancer after the Fukushima nuclear power plant accident. Thyroid 28(1): 11-22.

Zebregs S, van den Putte B, Neijens P, de Graaf A. 2015. The differential impact of statistical and narrative evidence on beliefs, attitude, and intention: A meta-analysis. Health Commun. 30(3): 282-289.

Cite this article as: Turcanu C, Perko T, Sala R, Wolf HV, Camps J, Oughton DH. 2020. Social uncertainties related to stable iodine intake in a nuclear emergency. Radioprotection 55(HS1): S163-S168 